УДК $65.012 .123: 005.71-021.131$

К. О. ЗАПАДНЯ ${ }^{1}$, О. А. ГАЙДЕНКО ${ }^{1}$, В. А. ПУЙДЕНКО 2

${ }^{1}$ Национальный аэрокосмический университет им. Н. Е. Жуковского «Харьковский авиационный институт», Украина

${ }^{2}$ Харьковский радиотехнический техникум, Украина

\title{
ВЫБОР И ОБОСНОВАНИЕ АРХИТЕКТУРЫ ВИРТУАЛЬНОЙ ПРОИЗВОДСТВЕННОЙ СИСТЕМЫ ДЛЯ ПЛАНИРУЕМОГО ПОРТФЕЛЯ ЗАКАЗОВ
}

\begin{abstract}
Поставлена и решена задача формирования и исследования функиионирования виртуальной производственной системы (ВПС) для планируемого портфеля заказов (ППЗ). Из-за сложности предлагаемой задачи, решение осуществляется поэтапно. На первом этапе проведено исследование основных показателей формируемой ВПС. В первую очередь, это касается состава ВПС, который должен по своим характеристикам соответствовать основным требованиям ППЗ. Для этого сформировано множество возможных предприятий - кандидатов ВПС с помощью базы прецедентов (БП). Для оценки каждого предприятия по основным показателям и требованиям ППЗ использована качественная шкала в виде букв латинского алфавита. Путём лексикографического упорядочивания вариантов в БП, осущзествляется выбор наиболее подходящих предприятий для организаџии ВПС. Для адаптаџии предприятий (оборудование, технологии) к конкретнылм требованиям ППЗ, осуществляется выбор мероприятий по модернизации производства. В качестве целевой функции, с помощьью которой оценивалось множество мероприятий, использованы затраты на проведение адаптации. В качестве ограничений, выступает время проведения мероприятий и допустимые риски. Для исследования функиионирования ВПС построена агентная имитационная модель, с помощью которой проведён анализ логистической иееи ВПС «снабжение - производство - сбыт». Результаты моделирования позволяют оценить сроки выполнения ППЗ, влияние проявления рисков и, в случае необходимости, провести дальнейшую перестройку архитектуры ВПС.

Предложенный подход иелесообразно использовать на начальном этапе организации и формирования архитектуры ВПС с учётом основных требований, связанных с планируемым портфелем заказов.
\end{abstract}

Ключевые слова: виртуальная производственная система, планируемый портфель заказов, адаптаџия прочзводства, оптимизачия затрат.

\section{Введение}

Динамика изменения характера спроса на рынках сбыта машиностроительной продукции (авиационное производство, космос, автомобилестроение и т.д.) требует оперативной перестройки производства под формируемый портфель заказов [1]. Новая форма организации производственного процесса основана на виртуализации и создании временной организационной структуры производства на базе существующих производственных мощностей [2]. Поэтому актуальна тема предлагаемой публикации, в которой обосновывается архитектура виртуальной производственной системы (ВПС), отвечающая требованиям и характеристикам планируемого портфеля заказов [3].

\section{Постановка задачи исследования}

Формирование организационной структуры
ВПС предполагает наличие производственных мощностей предприятий, которые можно временно задействовать в планируемом портфеле заказов (ППЗ). Каждое из предприятий можно охарактеризовать набором показателей, который должен соответствовать требованиям планируемого портфеля заказов. Множество предприятий, претендентов на получение заказа, представим в виде базы прецедентов (БП), в которой находятся готовые решения (производственные мощности, технологические процессы) [4]. Необходимо подобрать такие прецеденты из БП, которые наиболее подходят по своим характеристикам к требованиям ППЗ, а также имеют возможность участвовать в выполнении ППЗ на планируемом отрезке времени.

Поставленную задачу решим в четыре этапа:

1. Формальное представление множества возможных предприятий кандидатов в ППЗ в виде базы прецедентов.

2. Формирование состава виртуальной произ-

(c) К. О. Западня, О. А. Гайденко, В. А. Пуйденко 
водственной системы.

3. Оптимизация затрат, связанных с адаптацией производства под требования ППЗ.

4. Моделирование функционирования ВПС.

Для решения задачи исследования были использованы методы теории прецедентов, методы оптимизации и агентное имитационное моделирование.

\section{Решение задачи исследования}

Оценим каждое из возможных предприятийкандидатов, для участия в ППЗ, в виде следующего набора значений показателей:

1) соответствие номенклатуры изделий і-го предприятия требованиям ППЗ - NP;

2) соответствие производственной мощности и технологических процессов і-го предприятия требованиям ППЗ - РМ;

3) соответствие времени выпуска продукции i-го предприятия срокам выполнения заказа в ППЗ $\mathrm{TP}$;

4) соответствие качества выпускаемой продукции i-го предприятия требованиям качества ППЗ QP;

5) соответствие стоимости продукции і-го предприятия требованиям по стоимости в ППЗ - SP.

На начальном этапе, для выбора необходимых предприятий (в виде кандидатов) для участия в ППЗ воспользуемся качественными оценками экспертов по каждому из перечисленных показателей.

Оценки представим в виде букв латинского алфавита, со следующими качественными значениями:

А - наилучшее значение соответствия показателя требованиям ППз;

В - хорошее значение соответствия показателя требованиям ППЗ;

$\mathrm{C}$ - удовлетворительное значение соответствия показателя требованиям ППЗ;

D - менее удовлетворительное значение соответствия показателя требованиям ППЗ.

Каждое i-е предприятие, возможный кандидат в ППЗ, должен быть оценён экспертами и представлен в виде і-го «слова» со значениями А, В, C, D, которое будет находится в БП.

Далее, необходимо сформировать порядок важности показателей, для последующего выбора состава ВПС, используя БП, для каждого і-го вида номенклатуры. Назначенный порядок будет основой для формирования состава ВПС при выполнении ППЗ. Для этого воспользуемся лексикографическим упорядочиванием вариантов, в результате которого, получим упорядоченное множество предприятий по значениям A, B, C, D и с учётом важности показателей. Рассмотрим иллюстративный пример.
Пусть ряд важности показателей, будет выглядеть следующим образом:

$$
\text { NP, PM, SP, QP, TP. }
$$

Неупорядоченное множество предприятий в виде прецедентов в БП имеет вид:

$$
\begin{array}{lc}
\text { 1. B, A, A, C, D } & \text { 6. B, A, B, A, B } \\
\text { 2. A, B, B, C, C } & \text { 7. C, A, A, A, A } \\
\text { 3. C, A, A, B, C } & \text { 8. D, B, A, C, B } \\
\text { 4. B, A, B, C, B } & \text { 9. B, A, A, A, C } \\
\text { 5. A, B, B, D, C } & \text { 10. A, D, D, B, C }
\end{array}
$$

Произведём лексикографическое упорядочивание вариантов:

$$
\begin{aligned}
& \text { 2. A, B, B, C, C } \\
& \text { 5. A, B, B, D, C } \\
& \text { 10. A, D, D, B, C } \\
& \text { 9. B, A, A, A, C } \\
& \text { 1. B, A, A, C, D } \\
& \text { 6. B, A, B, A, B } \\
& \text { 4. B, A, B, C, B } \\
& \text { 7. C, A, A, A, A } \\
& \text { 3. C, A, A, B, C } \\
& \text { 8. D, B, A, C, B }
\end{aligned}
$$

Отбросим варианты с наихудшими D - значениями показателей. Получим:

$$
\begin{aligned}
& \text { 2. A, B, B, C, C } \\
& \text { 9. B, A, A, A, C } \\
& \text { 6. B, A, B, A, B } \\
& \text { 4. B, A, B, C, B } \\
& \text { 7. C, A, A, A, A } \\
& \text { 3. C, A, A, B, C }
\end{aligned}
$$

Если, руководство ВПС не удовлетворяют оценки, связанные со значением С, то окончательно получим:

$$
\text { 6. B, A, B, A, B }
$$

Сформированный состав предприятий, который будет участвовать в ППЗ, необходимо проанализировать с точки зрения проведения адаптации, необходимой для полного удовлетворения требований ППЗ. Для этого необходимо провести целый ряд мероприятий для каждого ј-го предприятия для обеспечения выпуска і-го изделия в ППЗ. Возникает задача оптимизации (минимизации) затрат на проведение мероприятий.

Представим затраты в виде целевой функции $\mathrm{W}$. Ограничением для проведения мероприятий будет время их проведения, а также возможные риски, как внутреннего, так и внешнего характера. Введём целочисленную переменную $\mathrm{x}_{\mathrm{ij}}$, для которой $\mathrm{x}_{\mathrm{ij}}=1$ означает, что для і-го элемента номенклатуры ППз 
выбрано j-е мероприятие и $\mathrm{x}_{\mathrm{ij}}=0$ - в противном случае.

Тогда целевая функция будет выглядеть следующим образом:

$$
\mathrm{W}=\sum_{\mathrm{i}=1}^{\mathrm{n}} \sum_{\mathrm{j}=1}^{\mathrm{n}_{\mathrm{i}}} \mathrm{w}_{\mathrm{ij}} \mathrm{x}_{\mathrm{ij}},
$$

где $\mathrm{n}$ - объем номенклатуры изделий ППЗ; $\mathrm{n}_{\mathrm{i}}$ - количество альтернативных мероприятий, которые необходимо выполнить для организации выпуска іго элемента номенклатуры ППЗ; $\mathrm{w}_{\mathrm{ij}}$ - затраты на проведение ј-го мероприятия для і-го элемента номенклатуры ППЗ.

В качестве ограничений необходимо использовать:

1. Время на проведение комплекса мероприятий по адаптации предприятий к выпуску продукции в ППЗ:

$$
\mathrm{T}=\sum_{\mathrm{i}=1}^{\mathrm{n}} \sum_{\mathrm{j}=1}^{\mathrm{n}_{\mathrm{i}}} \mathrm{t}_{\mathrm{ij}} \mathrm{x}_{\mathrm{ij}}, \quad \mathrm{T} \leq \mathrm{T}^{\prime},
$$

где $\mathrm{T}^{\prime}$ - допустимое время, выделенное на проведение мероприятий по адаптации продукции; $\mathrm{t}_{\mathrm{ij}}$ · время, затраченное на проведение ј-го мероприятия для і-го элемента номенклатуры выпуска в ППЗ.

2. Риски, связанные с проведением мероприятий (в том числе риски, связанные с выделением средств на проведение мероприятий):

$$
\mathrm{R}=\sum_{\mathrm{i}=1}^{\mathrm{n}} \sum_{\mathrm{j}=1}^{\mathrm{n}_{\mathrm{i}}} \mathrm{r}_{\mathrm{ij}} \mathrm{x}_{\mathrm{ij}}, \quad \mathrm{R} \leq \mathrm{R}^{\prime},
$$

где $\mathrm{R}^{\prime}$ - допустимое значение риска; $\mathrm{r}_{\mathrm{ij}}$ - значение возможного риска, связанное с проведением ј-го мероприятия для і-го элемента номенклатуры выпуска в ППЗ.

Необходимо решить следующую оптимизационную задачу:

$$
\min W, W=\sum_{i=1}^{n} \sum_{j=1}^{n_{i}} r_{i j} x_{i j},
$$

с учётом ограничений:

$$
\begin{gathered}
\mathrm{T} \leq \mathrm{T}^{\prime}, \mathrm{R}=\sum_{\mathrm{i}=1}^{\mathrm{n}} \sum_{\mathrm{j}=1}^{\mathrm{n}_{\mathrm{i}}} \mathrm{t}_{\mathrm{ij}} \mathrm{x}_{\mathrm{ij}}, \\
\mathrm{R} \leq \mathrm{R}^{\prime}, \mathrm{R}=\sum_{\mathrm{i}=1}^{\mathrm{n}} \sum_{j=1}^{\mathrm{n}_{\mathrm{i}}} \mathrm{r}_{\mathrm{ij}} \mathrm{x}_{\mathrm{ij}} .
\end{gathered}
$$

Для моделирования функционирования ВПС сформирован состав модульной имитационной модели, которая построена на основе агентного моделирования. Кроме моделирования материальных потоков внутри ВПС, проводилось исследование материальных потоков всей логистической цепи «снабжение-производство-сбыт» [5, 6]. Поэтому в состав «агентов» для исследования функционирования ВПС входят:

1. Агент «генерация заявок», для формирования заказов ВПС с использованием заданного ППЗ.

2. Агент «снабжение» имитирует материальные потоки снабжения ВПС.

3. Агент «компонента ВПС» имитирует работу отдельного элемента производственной структуры ВПС, используемого в конкретном заказе.

4. Агент «сбыт» имитирует материальный поток сбыта в ВПС.

5. Агент «управление заказами» имитирует последовательность и время начала выполнения заказов в ВПС в соответствии с заданным ППЗ.

6. Агент «монитор» формирует список будущих событий и следит за системным временем моделирования.

7. Агент «статистика» собирает статистику по работе каждого агента и всей ВПС в целом.

8. Агент «результаты» выдаёт результаты моделирования в виде сроков выполнения заказов и работы отдельных элементов агентной модели (очереди, простои, загрузка и т.д.).

На рис. 1 представлена структурная схема агентной имитационной модели для исследования ВПС.

\section{Выводы}

Предложенный подход целесообразно использовать на начальных этапах создания виртуальной производственной системы, когда необходимо в результате анализа рынка сбыта производственной продукции сформировать будущий портфель заказов предприятия.

\section{Литература}

1. Федорович, О. С. Наукові основи управління великомасштабними проектами та програмами: моногр. [Текст] / О. Е. Федорович, В. М. Ілюшко, Е. Ю. Рубін. - Х. : Наи. аэрокосм. ун-т «Харьк. авиац. ин-т», 2014. - 201 c.

2. Федорович, О. Е. Логистика выполнения портфеля заказов высокотехнологической продукциии развивающегося виртуального предприятия 


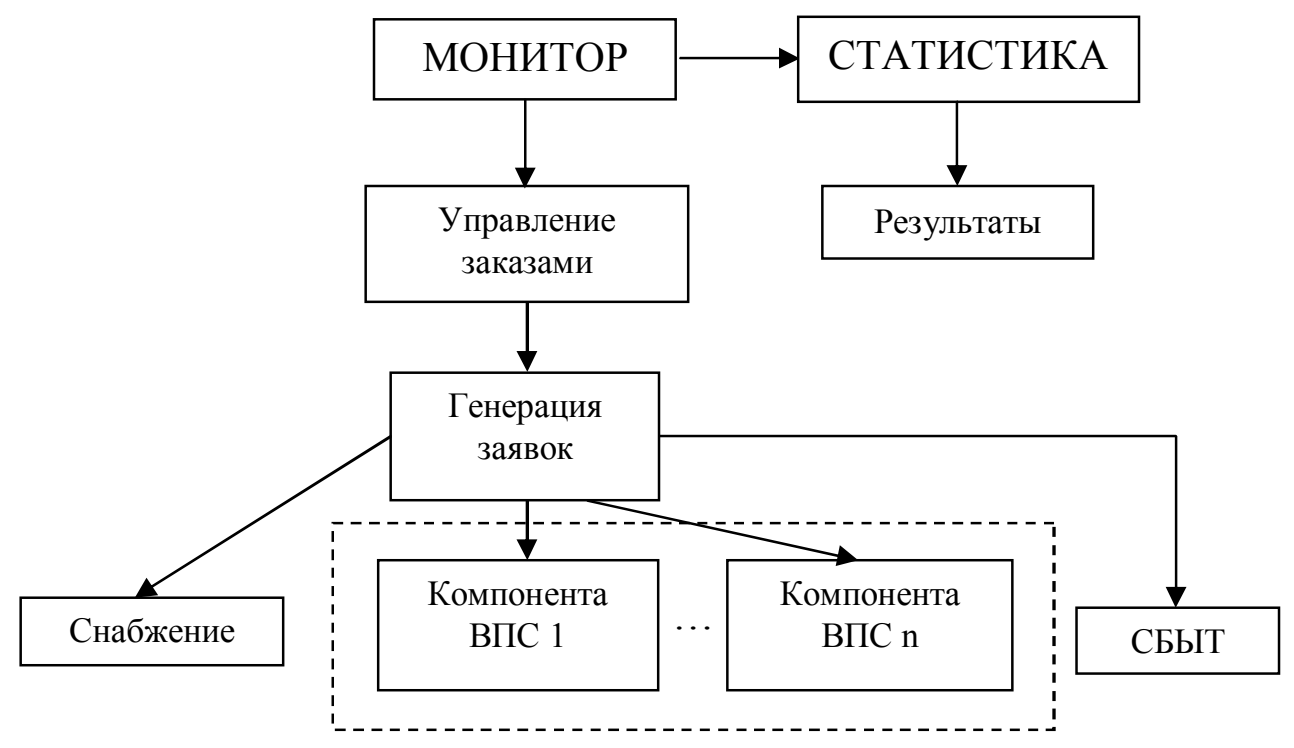

Рис. 1 Структурная схема агентной имитационной модели ВПС

[Текст] / О. Е. Федорович, Ю. Л. Прончаков // Авиациионно-космическая техника и технология. - 2016. №3(130). - C. 99-102.

2. Федорович, О. Е. Методы и модели исследования виртуальных производств, ориентированных на выпуск высокотехнологической продукиии [Текст] / О. Е. Федорович, К. О. Западня, О. А. Гайденко // Авиачионно-космическая техника и технология. - 2017. - №1(136). - С. 54-59.

3. Федорович, О. Е. Использование прецедентного похода для формирования плана мероприятий по повышению конкурентоспособности развивающегося предприятия [Текст] / O. Е. Федорович, K. О. Западня, М. В. Иванов // Радиоэлектроннье и компьютерные системы. - 2016. - №1(75). - С. 114 118.

4. Christopher, M. Logistics \& Supply Chain Management [Tекст] / M. Christopher. - Great Britain : Pearson Education Limited. - 2011. - 276 p.

5. Teimoury, E. An Integrated Queuing Model for Site Selection and Inventory Storage Planning of a Distribution Center with Customer Loss Consideration [Tекст] / E. Teimoury, I. G. Khondabi, M. Fathi // International Journal of Industrial Engineering \& Production Research. - 2011. - № 3. - P. 151-158.

\section{References}

1. Fedorovich, O. E., Ilyushko, V. M., Rubin, E. Yu. Naukovi osnovy upravlinnya velykomasshtabnymy proektamy ta prohramamy: monogr. [Scientific basis for large-scale projects and programs management]. Kharkov, Nac. ajerokosm. un-t «Har'k. aviac. in-t» Publ., 2014. 201 p.
2. Fedorovich, O. E., Pronchakov, Ju. L. Logistika vypolneniya portfelya zakazov vysokotekhnologicheskoy produktsii razvivayushchegosya virtual'nogo predpriyatiya [Logistics of the portfolio of orders execution for high-tech products of the developing virtual enterprise]. Aviacijno-kosmicna tehnika $i$ tehnologia - Aerospace technic and technology, 2016, no. 3(130), pp. 99-102.

3. Fedorovich, O. E., Zapadnya, K. O., Gaydenko, O. A. Metody i modeli issledovaniya virtual'nykh proizvodstv, oriyentirovannykh na vypusk vysokotekhnologicheskoy produktsii [Methods and models of research of virtual productions focused on production of high-tech products]. Aviacijno-kosmicna tehnika $i$ tehnologia - Aerospace technic and technology, 2017, no. 1(136), pp. 54-59.

4. Fedorovich, O. E., Zapadnya, K. O., Ivanov M. V. Ispol'zovaniye pretsedentnogo pokhoda dlya formirovaniya plana meropriyatiy po povysheniyu konkurentosposobnosti razvivayushchegosya predpriyatiya [Use of a precedent approach to make the plan of actions on increase of competitiveness of the developing enterprise]. Radioelektronni i komp'uterni sistemi - Radioelectronic and computer systems, 2016, no. 1(75), pp. 114-118.

5. Christopher, M. Logistics \& Supply Chain Management. Great Britain, Pearson Education Limited Publ., 2011. 276 p.

6. Teimoury, E., Khondabi, I. G., Fathi, M. An Integrated Queuing Model for Site Selection and Inventory Storage Planning of a Distribution Center with Customer Loss Consideration. International Journal of Industrial Engineering \& Production Research, 2011, no. 3, pp. $151-158$. 


\section{ВИБІР І ОБГРУНТУВАННЯ АРХІТЕКТУРИ ВІРТУАЛЬНОЇ ВИРОБНИЧОЇ СИСТЕМИ ДЛЯ ПЛАНОВАНОГО ПОРТФЕЛЯ ЗАМОВЛЕНЬ}

\section{К. О. Западня, О. О. Гайденко, В.О. Пуйденко}

Поставлено та розв'язано задачу формування та дослідження функціонування віртуальної виробничої системи (ВВС) для планованого портфеля замовлень (ППЗ). Через складність запропонованої задачі, рішення здійснюється поетапно. На першому етапі проведено дослідження основних показників формованої ВПС. В першу чергу, це стосується складу ВВС, який повинен за своїми характеристиками відповідати основним вимогам ППЗ. Для цього сформовано множину можливих підприємств - кандидатів ВВС за допомогою бази прецедентів (БП). Для оцінки кожного підприємства за основними показниками і вимогами ППЗ використано якісну шкалу у вигляді букв латинського алфавіту. Шляхом лексикографічного впорядкування варіантів в БП здійснюється вибір найбільш придатних підприємств для організації ВВС. Для адаптації підприємств (обладнання, технології) до конкретних вимог ППЗ здійснюється вибір заходів з модернізації виробництва. В якості цільової функції, за допомогою якої оцінюється безліч заходів, використано витрати на проведення адаптації. Як обмеження виступає час проведення заходів та допустимі ризики. Для дослідження функціонування ВВС побудовано агентну імітаційну модель, за допомогою якої проведено аналіз логістичного ланцюга ВВС «постачання - виробництво - збут». Результати моделювання дозволяють оцінити терміни виконання ППЗ, вплив прояви ризиків і, в разі необхідності, провести подальшу перебудову архітектури ВВС.

Запропонований підхід доцільно використовувати на початковому етапі організації і формування архітектури ВВС з урахуванням основних вимог, пов'язаних з планованим портфелем замовлень.

Ключові слова: віртуальна виробнича система, планований портфель замовлень, адаптація виробництва, оптимізація витрат.

\section{SELECTION AND JUSTIFICATION OF ARCHITECTURE OF VIRTUAL PRODUCTION SYSTEM FOR PLANNED PORTFOLIO OF ORDERS}

\section{K. O. Zapadnya, O. A. Gaydenko, V. A. Puydenko}

The task to form and research the virtual production system (VPS) operation for the planned portfolio of orders (PPO) has been stated and solved. Due to the complexity of the proposed task, the solution is implemented in several stages. At the first stage the research of the main indicators of the formed VPS has been made. First of all, this concerns the composition of the VPS that according to its characteristics should meet the basic requirements of the PPO. For this purpose a set of potential enterprises - VPS candidates - have been formed using a precedent base (PB). A qualitative scale in the form of Latin alphabet was used to evaluate each enterprise in terms of key indicators and requirements of PPO. By lexicographic ordering of options in the PB, the most suitable enterprises are selected to make the VPS. To adapt the enterprises (equipment, technologies) to the specific requirements of PPO, the choice of activities for the modernization of production is made. The adaptation costs have been selected as an objective function to evaluate the set of activities. The time to make the activities and the acceptable risks are taken as limitations for the task. In order to study the VPS operation an agent simulation model has been constructed. The analysis of the VPS "supply-production-marketing" logistics chain has been carried out on the basis of this model. The results of the simulation make it possible to estimate the time of PPO implementation, the impact of the risks and, if necessary, to make the further restructuring of the VPS architecture.

The proposed approach is expedient to be used at the initial stage of VPS architecture development taking into account the basic requirements associated with the planned portfolio of orders.

Keywords: virtual production system, planned portfolio of orders, production adaptation, cost optimization.

Западня Ксения Олеговна - канд. техн. наук, научный сотрудник каф. информационных управляющих систем, Национальный аэрокосмический университет им. Н. Е. Жуковского «Харьковский авиационный институт», Харьков, Украина, e-mail: k.zapadnya@khai.edu.

Гайденко Олег Александрович - аспирант каф. информационных управляющих систем, Национальный аэрокосмический университет им. Н. Е. Жуковского «Харьковский авиационный институт», Харьков, Украина, e-mail: o.gaydenko@khai.edu.

Пуйденко Вадим Алексеевич - преподаватель компьютерных дисциплин, специалист высшей категории, Харьковский радиотехнический техникум, Харьков, Украина, e-mail: vapuydenko@gmail.com.

Zapadnya Ksenia Olegovna - PhD, the research associate of department of information managing directors of systems, National Aerospace University «Kharkiv Aviation Institute», Kharkiv, Ukraine, e-mail: k.zapadnya@khai.edu.

Gaidenko Oleg Aleksandrovitch - PhD student of department of information managing directors of systems, National Aerospace University «Kharkiv Aviation Institute», Kharkiv, Ukraine, e-mail: o.gaydenko@khai.edu.

Puydenko Vadim Alekseevich - teacher of computer disciplines, the expert of the highest category, Kharkov radio technical school, Kharkiv, Ukraine, e-mail: vapuydenko@gmail.com. 